\title{
3-Mercapto-2,6-Pyridinedicarboxylic Acid: A Small Lanthanide-Binding Tag for Protein Studies by NMR Spectroscopy
}

\author{
Bradley Man, ${ }^{[b]}$ Xun-Cheng Su, ${ }^{[a]}$ Haobo Liang, ${ }^{[a]}$ Shane Simonsen, ${ }^{[a]}$ Thomas Huber, ${ }^{[c]}$ \\ Barbara A. Messerle, ${ }^{[b]}$ and Gottfried Otting*[a]
}

\begin{abstract}
Paramagnetic effects from lanthanide ions present powerful tools for protein studies by nuclear magnetic resonance (NMR) spectroscopy provided that the lanthanide can be site-specifically and rigidly attached to the protein. A new, particularly small and rigid lanthanide-binding tag, 3-mercapto-2,6-pyridinedicarboxylic acid (3MDPA), was synthesized and attached to two different proteins via a
\end{abstract}

disulfide bond. The complexes of the $\mathrm{N}$-terminal domain of the E. coli arginine repressor $(\operatorname{ArgN})$ with seven different paramagnetic lanthanide ions and $\mathrm{Co}^{2+}$ were analyzed in detail by

Keywords: lanthanides magnetic properties - NMR spectroscopy $\cdot$ protein labeling pseudocontact shifts
NMR spectroscopy. The magnetic susceptibility anisotropy $(\Delta \chi)$ tensors and metal position were determined from pseudocontact shifts. The 3MDPA tag generated very different $\Delta \chi$ tensor orientations compared to the previously studied 4-mercaptomethyl-DPA tag, making it a highly complementary and useful tool for protein NMR studies.

\section{Introduction}

Paramagnetic metal ions create pronounced effects in protein NMR spectra, offering a rich source of long-range structural restraints, which are readily available for many metalloproteins (for a review see, e.g., ref. [1]). With the advent of reagents for site-specific attachment of metal ions to nonmetalloproteins, the power of paramagnetic NMR spectroscopy can also be harnessed for otherwise diamagnetic proteins. This has triggered the development of metal tags that can generate the full range of paramagnetic effects (for reviews, see refs. [2] and [3]). Many of the tags are large, flexible or difficult to synthesize. Here, we present a tag that can

[a] Dr. X.-C. Su, Dr. H. Liang, Dr. S. Simonsen, Prof. G. Otting Research School of Chemistry, Australian National University Canberra ACT 0200 (Australia)

Fax: (+61)2-61250750

E-mail: gottfried.otting@anu.edu.au

[b] B. Man, Prof. B. A. Messerle

School of Chemistry, University of New South Wales Sydney NSW 2052 (Australia)

[c] Dr. T. Huber

School of Chemistry and Molecular Biosciences University of Queensland, Brisbane QLD 4072 (Australia)

Supporting information for this article is available on the WWW under http://dx.doi.org/10.1002/chem.200902904. be synthesized in few steps and is smaller than any other lanthanide-binding tag described previously.

Among the paramagnetic NMR effects, pseudocontact shifts (PCS) contain particularly valuable structural information. The PCS $\Delta \delta^{\mathrm{PCS}}$ (in ppm) of a nuclear spin depends on its polar coordinates $r, \theta$ and $\phi$ with respect to the principal axes of the magnetic susceptibility anisotropy tensor $(\Delta \chi$ tensor): $:^{[4]}$

$\Delta \delta^{\mathrm{PCS}}=\frac{1}{12 \pi r^{3}}\left[\Delta \chi_{\mathrm{ax}}\left(3 \cos ^{2} \theta-1\right)+\frac{3}{2} \Delta \chi_{\mathrm{rh}} \sin ^{2} \theta \cos 2 \varphi\right]$

where $\Delta \chi_{\mathrm{ax}}$ and $\Delta \chi_{\mathrm{rh}}$ denote, respectively, the axial and rhombic components of the $\Delta \chi$ tensor. The $\Delta \chi$ tensor is the anisotropic component of the magnetic susceptibility tensor $\chi$ describing the magnetic moment of the paramagnetic centre. It is centred on the metal ion and its principal axes define a coordinate frame anchored to the protein. As PCSs report on the position of nuclear spins with respect to this coordinate system and PCSs of lanthanides can be measured for nuclear spins located as far as $40 \AA$ from the metal ion, ${ }^{[5]}$ they are ideally suited for the determination of the 3D structure of a protein-protein complex by rigid-body docking, or the determination of the structure and binding mode of small compounds binding to a paramagnetically labelled protein. ${ }^{[6,7]}$ 
High-spin $\mathrm{Co}^{2+}$ and paramagnetic lanthanide ions (except $\mathrm{Gd}^{3+}$ ) generate large PCS effects compared to the enhancement of nuclear relaxation that is invariably associated with paramagnetic metals. In addition, $\mathrm{Zn}^{2+}, \mathrm{La}^{3+}, \mathrm{Y}^{3+}$ and $\mathrm{Lu}^{3+}$ are diamagnetic ions that can substitute $\mathrm{Co}^{2+}$ and lanthanide ions, respectively, in practically all coordination environments. This provides good diamagnetic references for accurate measurements of PCSs. In order to use Equation (1), however, the metal ions must be attached rigidly to their protein targets in a site-specific manner.

Different strategies for site-specific attachment of $\mathrm{Co}^{2+}$ and lanthanides to proteins have been developed, including $\mathrm{N}$ - and C-terminal fusions of lanthanide-binding peptides, ${ }^{[8,9]}$ disulfide-bond formation of lanthanide-binding peptides and lanthanide-chelating molecules with cysteine residues ${ }^{[9-16]}$ and noncovalent association of lanthanide complexes. ${ }^{[17]}$ The smallest metal tag to date is 4-mercaptomethylene-dipicolinic acid (4MMDPA). ${ }^{[10]}$ DPA stands out for its nanomolar affinity for lanthanide ions despite providing few coordination sites $^{[18]}$ and for nonchiral metal coordination, avoiding the formation of diastereomers when bound to proteins. ${ }^{[16,19]}$

A small size is advantageous for a metal ion binding tag. Small tags are less likely to interfere with the natural function of a protein than large tags. In addition, attachment of the metal ion in close proximity of the protein surface facilitates the accurate determination of the $\Delta \chi$ tensor by placing more nuclear spins near the metal ion. Finally, a short tether and a rigid tag reduce the chance of large amplitude motions of the metal ion with respect to the protein, which would result in significant averaging of the PCSs. As PCSs can assume positive or negative signs [Eq. (1)], averaging tends to decrease their magnitude severely. A variable metal position also prevents fitting of the PCSs by a single $\Delta \chi$ tensor.

In order to immobilize the metal ion on a protein surface, tags have been developed that provide two attachment points. ${ }^{[9,14]}$ A similar effect can be achieved with tags attached by a single covalent bond if the metal has free coordination sites left to associate, in addition, with an aminoacid side-chain of the protein. ${ }^{[10]}$

In the following, we present a new tag, 3-mercapto-2,6pyridinedicarboxylic acid (3MDPA, 3) and explore its lanthanide and cobalt ion binding properties when bound to two different proteins, the N-terminal DNA-binding domain of the E. coli arginine repressor (ArgN) and the C54T/ C97A/Q69C triple mutant of T4 lysozyme.

\section{Results}

Synthesis of 3MDPA (2 b): The synthesis of 3-mercapto-2,6pyridinedicarboxylic acid (2b) is depicted in Scheme 1. The synthesis starts with commercially available 2,6-lutidine. The bromide 1 was obtained by using the protocol by Zimmermann et al. ${ }^{[20]}$ Stirring bromide $\mathbf{1}$ in a suspension of sodium tert-butyl thiolate in tetrahydrofuran under Schlenk conditions yielded the thiol ether $\mathbf{2 a}$, which was used without fur-
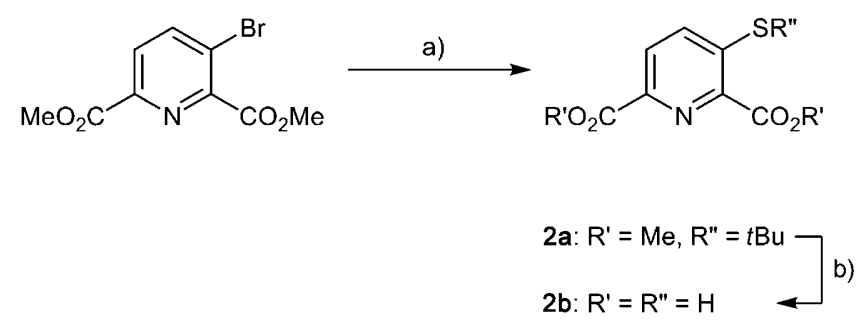

Scheme 1. Synthesis of 3-mercapto-2,6-pyridinedicarboxylic acid (3MDPA, 2b): a) $\mathrm{NaStBu}$, THF; b) concentrated $\mathrm{HCl}$, reflux.

ther purification. The protecting groups were removed by refluxing the thiol ether in concentrated hydrochloric acid and the resulting suspension was filtered to yield 3MDPA (2b) with sufficient purity to be used for protein derivatization without additional purification.

Tagging of proteins with 3MDPA (2b): Uniformly ${ }^{15} \mathrm{~N}-\mathrm{la}-$ belled samples of ArgN and of the C54T/C97A/Q69C triple mutant of T4 lysozyme were derivatized by using 5,5'-dithiobis(2-nitrobenzoic acid) (DTNB) to activate the cysteine residues of the proteins, followed by reaction with 3MDPA, as described previously. ${ }^{[11]}$ Disulfide bond formation yielded the adducts ArgN-3MDPA and T4 lysozyme-3MDPA, respectively. The derivatized proteins were purified by FPLC on an ion-exchange column.

NMR resonance assignment of the ArgN-3MDPA adduct: The ${ }^{15} \mathrm{~N}-\mathrm{HSQC}$ spectrum of ArgN-3MDPA showed broad lines for amino acid residues in the vicinity of Cys68, indicating conformational exchange on the millisecond time scale. Titration of the sample with $\mathrm{YCl}_{3}$ to form a 1:1 complex resulted in a single set of peaks, suggesting that the metal ion locked the adduct in a single conformational species. Alternatively, the presence of the metal ion might have accelerated the conformational exchange, although it is difficult to visualize how the bulkier DPA-metal complex could bring the system into the fast-exchange regime. In the course of the titration, cross-peaks of the ArgN-3MDPA$\mathrm{Y}^{3+}$ complex appeared as the cross-peaks of ArgN-3MDPA vanished, indicating that the exchange of the metal ion is slow.

Some of the ${ }^{15} \mathrm{~N}-\mathrm{HSQC}$ cross-peaks of the ArgN$3 \mathrm{MDPA}-\mathrm{Y}^{3+}$ complex were significantly shifted compared to those of unmodified ArgN. Therefore, the resonance assignments were re-established by a 3D NOESY $-{ }^{15} \mathrm{~N}-\mathrm{HSQC}$ spectrum. The NOEs showed no evidence of a significant change in structure. Structural conservation was also suggested by the observation that chemical-shift changes were confined to the vicinity of Cys68.

PCS measurements of ArgN-3MDPA: The 1:1 complexes of ArgN-3MDPA with different lanthanides resulted in significant PCSs. Measurements were performed with $\mathrm{Ce}^{3+}$ $\mathrm{Tb}^{3+}, \mathrm{Dy}^{3+}, \mathrm{Ho}^{3+}, \mathrm{Er}^{3+}, \mathrm{Tm}^{3+}, \mathrm{Yb}^{3+}$ by using $\mathrm{Y}^{3+}$ as the diamagnetic reference. In addition, spectra were recorded 
with $\mathrm{Co}^{2+}$ by using $\mathrm{Zn}^{2+}$ as the diamagnetic reference (Figure 1).

The lanthanide binding affinity of $\operatorname{ArgN}-3 \mathrm{MDPA}$ is weaker than that of ArgN-4MMDPA, as the addition of DPA to a solution of ArgN-3MDPA quantitatively regenerated the apo-protein. Under the same conditions, ArgN-
4MMDPA released only a fraction of the lanthanides to DPA. Despite the weaker binding affinity of $\mathrm{ArgN}-$ 3MDPA, attempts to generate exchange cross-peaks in samples containing mixtures of paramagnetic and diamagnetic metal ions ${ }^{[21]}$ failed, indicating that the exchange rates are of the order of seconds or longer. The slow metal exchange rate was beneficial in allowing the simultaneous observation of paramagnetic and diamagnetic cross-peaks in samples prepared with a mixture of paramagnetic and diamagnetic metal ions. The PCSs could thus be measured accurately from a single spectrum, where both species experienced exactly the same conditions of temperature, $\mathrm{pH}$, protein concentration, ionic strength, etc.

The assignment of the paramagnetic peaks was assisted by the fact that the proton and nitrogen spin of an amide experience similar PCSs because their coordinates differ little compared to the distance from the paramagnetic centre. Therefore, the paramagnetic cross-peaks are displaced along approximately parallel lines from their diamagnetic partner.

The resonance assignments were supported further by the use of different paramagnetic metal ions. For example, $\mathrm{Tb}^{3+}$ and $\mathrm{Tm}^{3+}$ not only displace the cross-peaks in opposite directions (Figure $1 \mathrm{~A}$ ) due to their opposite sign of tensor anisotropies, ${ }^{[6]}$ but the slopes of displacement are closely similar for any given diamagnetic cross-peak, as the geometry of the ${ }^{1} \mathrm{H}-{ }^{15} \mathrm{~N}$ group with respect to the paramagnetic centre remains unchanged if the metal position is conserved. The slope of cross-peak displacement for different metals is expected to be the same even in the presence of residual anisotropic chemical shifts (RACS), ${ }^{[22]}$ as long as the principal axes of the $\Delta \chi$ tensors of the different metals are similarly orientated and of similar relative magnitude. 
Metal position and $\Delta \chi$ tensors: The PCSs were used together with the NMR structure of $\mathrm{ArgN}^{[23]}$ to determine the position and orientations of the $\Delta \chi$ tensors associated with the different metal ions in multiple rounds of fitting tensor parameters and assigning additional paramagnetic cross-peaks, assuming that all metal ions occupy a common position with respect to the protein. Figure 2 illustrates the metal position and the principal axes of the $\Delta \chi$ tensors obtained. The metal ion is positioned about $3.2 \AA$ from the carboxyl group of Glu21. The $z$ axes of the $\Delta \chi$ tensors of all metal ions have similar orientations (with some ambiguity in the cases of $\mathrm{Er}^{3+}$ and $\mathrm{Tm}^{3+}$ for which the $z$ and $y$ axes were of similar magnitude), suggesting that the coordination geometry is similar for all metals. The orientations of the $x$ and $y$ axes are less well conserved, which may in part be attributed to the greater uncertainty associated with the rhombic component of the $\Delta \chi$ tensor. The magnitudes of the axial components of the $\Delta \chi$ tensors decreased as follows: $\mathrm{Dy}^{3+}>\mathrm{Ho}^{3+}>$ $\mathrm{Tb}^{3+}>\mathrm{Tm}^{3+}>\mathrm{Co}^{2+}>\mathrm{Yb}^{3+}>\mathrm{Er}^{3+}>\mathrm{Ce}^{3+}$ (Table 1). $\mathrm{Co}^{2+}$ produced less paramagnetic relaxation enhancement than $\mathrm{Yb}^{3+}$, allowing the observation of some very large PCSs of nuclear spins close to the metal ion (Figure 1B).

Most PCSs observed with lanthanides were of opposite sign from those observed previously with corresponding complexes of ArgN-4MMDPA. ${ }^{[10]}$ As 4MMDPA was attached to Cys68 in complete analogy to the ArgN-3MDPA adduct, this result indicates that the 3MDPA tag is suitable for generating new tensor orientations for the same protein.

NMR analysis of T4 lysozyme3MDPA-metal complexes: Using the same protocol as for ArgN, the 3MDPA tag was attached to the C54T/C97A/ Q69C triple mutant of uniformly ${ }^{15} \mathrm{~N}$-labelled $\mathrm{T} 4$ lysozyme, the ${ }^{15} \mathrm{~N}$-HSQC cross-peaks of the T4 lysozyme-3MDPA- $\mathrm{Lu}^{3+}$ complex were assigned by using a 3D NOESY- ${ }^{15} \mathrm{~N}-H S Q C$ spectrum and PCSs were measured for complexes with $\mathrm{Tm}^{3+}$ and $\mathrm{Co}^{2+}$. The magnitude of PCSs observed was similar for both metal ions. Comparison with the corresponding $\mathrm{Tm}^{3+}$ complex of the 4MMDPA adduct showed that, as in the case of ArgN, the PCSs tended to be of opposite sign between both constructs (Figure S3B in the Supporting Information). In ure S6 in the Supporting Information).

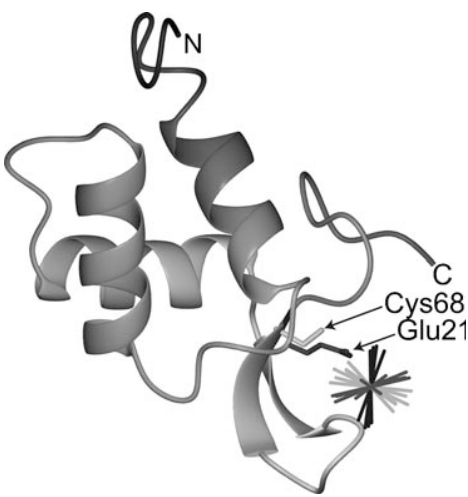

Figure 2. The $\Delta \chi$ tensors of eight different metal ions bound to the ArgN-3DPA adduct. The $x, y$ and $z$ axes of the $\Delta \chi$ tensors are distinguished by light grey, dark grey and black lines, respectively. The axes definitions follow the unique tensor representation (UTR) convention, in which the $x$ and $z$ axes are the shortest and longest axes of the tensor. ${ }^{[30]}$ The side chains of Glu12 and Cys68 and the $\mathrm{N}$ and C termini of the protein are labelled. The figure was generated by using MOLMOL. ${ }^{[31]}$

Table 1. The $\Delta \chi$ tensors of different metal ions in complex with ArgN-3MDPA. ${ }^{[\mathrm{a}]}$

\begin{tabular}{|c|c|c|c|c|c|c|}
\hline Metal ion & $\Delta \chi_{\mathrm{ax}}$ & $\Delta \chi_{\mathrm{rh}}$ & Tensor & & tes of te & \\
\hline $\mathrm{Ce}^{3+}$ & $-0.3(0.1)$ & $0.0(0.05)$ & $x$ & -0.189 & 0.982 & -0.007 \\
\hline & & & $y$ & 0.820 & 0.162 & 0.549 \\
\hline & & & $z$ & 0.541 & 0.098 & -0.836 \\
\hline $\mathrm{Tb}^{3+}$ & $-8.1(0.9)$ & $-2.5(0.5)$ & $x$ & 0.237 & -0.911 & 0.338 \\
\hline & & & $y$ & 0.558 & 0.413 & 0.720 \\
\hline & & & $z$ & -0.795 & 0.018 & 0.606 \\
\hline $\mathrm{Dy}^{3+}$ & $-17.0(1.5)$ & $-1.4(0.9)$ & $x$ & 0.099 & -0.978 & 0.182 \\
\hline & & & $y$ & 0.660 & 0.202 & 0.723 \\
\hline & & & $z$ & -0.744 & 0.049 & 0.666 \\
\hline $\mathrm{Ho}^{3+}$ & $-9.8(0.9)$ & $-1.0(0.5)$ & $x$ & -0.025 & 0.999 & 0.024 \\
\hline & & & $y$ & 0.692 & 0.000 & 0.722 \\
\hline & & & $z$ & 0.722 & 0.035 & -0.691 \\
\hline $\mathrm{Er}^{3+}$ & $2.9^{[\mathrm{b}]}$ & $1.2^{[\mathrm{b}]}$ & $x$ & -0.028 & -0.524 & 0.851 \\
\hline & & & $y$ & 0.401 & 0.774 & 0.490 \\
\hline & & & $z$ & -0.916 & 0.355 & 0.189 \\
\hline $\mathrm{Tm}^{3+}$ & $6.6^{[\mathrm{b}]}$ & $2.4^{[\mathrm{b}]}$ & $x$ & 0.229 & -0.834 & 0.503 \\
\hline & & & $y$ & 0.530 & 0.540 & 0.654 \\
\hline & & & $z$ & -0.817 & 0.117 & 0.565 \\
\hline $\mathrm{Yb}^{3+}$ & $3.4(0.9)$ & $0.8(0.4)$ & $x$ & 0.089 & -0.973 & 0.211 \\
\hline & & & $y$ & 0.685 & 0.214 & 0.697 \\
\hline & & & $z$ & -0.723 & 0.083 & 0.686 \\
\hline $\mathrm{Co}^{2+}$ & $-4.6(0.4)$ & $-0.6(0.2)$ & $x$ & 0.335 & -0.699 & 0.632 \\
\hline & & & $y$ & 0.681 & 0.643 & 0.350 \\
\hline & & & $z$ & -0.651 & 0.313 & 0.692 \\
\hline
\end{tabular}

[a] At $25^{\circ} \mathrm{C}$ and $\mathrm{pH} 6.5$ in $20 \mathrm{~mm}$ MES buffer. The tensors are listed in their unique tensor representation $(\mathrm{UTR})^{[30]}$ as obtained by fitting of the PCSs to the first conformer of the PDB ID 2AOY of ArgN. ${ }^{[23]}$ The orientations of the tensor axes are given with respect to the origin $(0,0,0)$. Standard deviations (shown in brackets) were determined by repeating the fits 100-times following random removal of $20 \%$ of the data. The common metal position obtained by the fit is $(12.112,8.600,2.893)$ with a standard deviation of about $\pm 0.4 \AA$ in each of the dimensions. The accuracy of the orientations of the tensor axes can be assessed by the SansonFlamsteed plots shown in the Supporting Information. [b] No standard deviation was determined for this metal ion because the $z$ and $y$ axes of the tensors were of similar magnitude and swapped in different fits (Fig- 


\section{Discussion}

The 3MDPA tag presents the smallest metal binding tag described to date that can bind lanthanide ions and be linked to a protein via a disulfide bond. A short linker between the metal ion and the protein has significant advantages. Firstly, $\Delta \chi$ tensors can be determined with greater accuracy if PCSs can be measured for nuclear spins that populate the largest possible angular space around the metal ion. Secondly, the metal ion is more readily immobilized with respect to the protein if the tether between protein and tag has fewer rotatable bonds and, finally, the tag is less likely to interfere with the biological function of the protein if it is small.

We observed for two different proteins that the 3MDPA tag orients the $\Delta \chi$ tensors of paramagnetic metal ions differently relative to the protein than the 4MMDPA tag described earlier. ${ }^{[10]}$ This shows that a small difference in chemical structure of the tag can change the $\Delta \chi$ tensor as much as different attachment points of lanthanide-binding peptides. ${ }^{[13]}$ Generating different $\Delta \chi$ tensor orientations by different tags is useful, as the orientations of the tensor axes obtained for the different metal ions tend to be similar (Figure 2). A similar situation has been observed previously for the $\Delta \chi$ tensors of different lanthanides bound to calbin$\operatorname{din} \mathrm{D}_{9 \mathrm{k}}{ }^{[24]}$ PCS data from differently oriented $\Delta \chi$ tensors are of great benefit, when models of protein-protein and protein-ligand complexes are to be established by using PCSs only. ${ }^{[25]}$

In the case of the previously studied ArgN-4MMDPA adduct, coordination of a lanthanide ion by the tag is complemented by coordination to the carboxyl group of Glu21, resulting in an effective two-point attachment of the lanthanide and immobilization of the lanthanide with respect to the protein. ${ }^{[10]}$ In the case of the ArgN-3MDPA adduct, the $\Delta \chi$ tensor fits of the different paramagnetic metal ions by using a common metal position resulted in a metal position that seems to be too far from the carboxyl oxygens of Glu21 to allow direct contacts (about $3 \AA$ ). Nevertheless, the electrostatic interaction between the metal ion and the sidechain carboxylate of Glu21 might be sufficiently strong to suppress the conformational exchange that leads to line broadening in ArgN-3MDPA in the absence of metal ions.

The $\Delta \chi_{\mathrm{ax}}$ values of the ArgN-3MDPA complexes with $\mathrm{Tb}^{3+}, \mathrm{Tm}^{3+}, \mathrm{Yb}^{3+}$ (Table 1 ) were about $40 \%$ smaller than those observed for the corresponding complexes with ArgN-4MMDPA. ${ }^{[10]}$ This makes the 3MDPA tag less attractive for measurements of residual dipolar couplings, but the PCSs are nonetheless sufficiently large to be used for protein-structure refinements and studies of protein-ligand complexes.

The magnitudes of $\Delta \chi$ tensors obtained for the same metal ion in slightly different chemical environments can vary for a number of reasons. 1) The weaker association of the lanthanides with the carboxyl group might be a contributing factor, by changing the ligand field and allowing more motions of the metal ion with respect to the protein. 2) The sulfur in 3MDPA is in close contact with one of the carboxyl groups. The crystal structure of 3-mercapto-2-pyridinecarboxylic acid shows, however, that the carboxyl group can remain coplanar with the pyridine ring. ${ }^{[2]}$ The close proximity of the sulfur could nonetheless subtly affect the ligand field of metal coordination, which might explain the observation that the NMR spectra of the $\mathrm{Co}^{2+}$ complexes of the 4MMDPA derivatives of $\mathrm{ArgN}$ and the C54T/C97A/ Q69C triple mutant of T4 lysozyme displayed only very small PCSs (data not shown) whereas $\mathrm{Co}^{2+}$ produced large PCSs with the 3MDPA derivatives (Figure $1 \mathrm{~B}$ and Figure $\mathrm{S} 2 \mathrm{~A}$ in the Supporting Information). 3) Even with PCSs from many different metal ions, it is difficult to pinpoint the position of the metal ion with high accuracy. ${ }^{15} \mathrm{~N}-\mathrm{HSQC}$ cross-peaks of amides in the vicinity of the metal ion are invariably broadened beyond detection, cross-peaks with very large PCSs are more difficult to assign, and a metal position at a greater distance from the protein can always be compensated to some extent by a larger $\Delta \chi$ tensor.

Sorting the lanthanides by the magnitude of their $\Delta \chi_{\mathrm{ax}}$ values observed in ArgN-3MDPA yielded a different sequence than the previously published values of lanthanide complexes of calbindin $\mathrm{D}_{9 \mathrm{k}} \cdot{ }^{\left[{ }^{[2]}\right.}$ For example, the $\Delta \chi$ tensor of $\mathrm{Ho}^{3+}$ was larger than that of $\mathrm{Tb}^{3+}$ and the $\Delta \chi$ tensor of $\mathrm{Er}^{3+}$ was smaller than that of $\mathrm{Yb}^{3+}$ (Table 1). This suggests that the $\chi$ tensor anisotropies of the lanthanides critically depend on their chemical environment and are difficult to predict quantitatively. Another example is the observation of a significantly larger $\chi$ tensor anisotropy for $\mathrm{Tm}^{3+}$ than for $\mathrm{Dy}^{3+}$ in the lanthanide binding tag CLaNP-5, ${ }^{[12]}$ although in most other cases the $\chi$ tensor anisotropy of $\mathrm{Dy}^{3+}$ is rivalled only by $\mathrm{Tb}^{3+} \cdot[24,27-29]$

\section{Conclusion}

The 3MDPA is a new metal tag that can generate significant PCSs with lanthanide ions and $\mathrm{Co}^{2+}$. Its small size and rigid structure improves the chances to immobilize metal ions close to protein surfaces and it produces PCSs that are complementary to PCS data obtained with the previously published 4MMDPA tag. These properties make it an attractive addition to the increasing number of metal tags designed for site-specific attachment of paramagnetic metal ions to proteins.

\section{Experimental Section}

General: 2,6-Lutidine and fuming sulfuric acid were purchased from $\mathrm{Al}$ drich and were used as received. 3-Bromo-2,6-dimethoxycarbonylpyridine (1) was prepared by using literature methods. ${ }^{[20]}$ Bulk compressed nitrogen $(>99.5 \%)$ was obtained from Linde Gas Pty and used as supplied. Melting points were determined by using a Gallenkamp melting apparatus and are uncorrected. ${ }^{1} \mathrm{H}$ and ${ }^{13} \mathrm{C}\left\{{ }^{1} \mathrm{H}\right\}$ NMR spectra were recorded on Bruker NMR spectrometers operating at ${ }^{1} \mathrm{H}$ NMR frequencies of either 300, 600 or $800 \mathrm{MHz}$. Chemical shifts were internally referenced to the residual solvent peak and all spectra recorded at $25^{\circ} \mathrm{C}$. The NMR 
spectra of the organic compounds were assigned by ${ }^{13} \mathrm{C}-\mathrm{HMBC}$ and ${ }^{13} \mathrm{C}$ HSQC spectra.

3-Mercapto-2,6-pyridinedicarboxylic acid (2b): A suspension of sodium tert-butylthiolate $(78.9 \mathrm{mg}, 0.7 \mathrm{mmol})$ and $\mathbf{1}(100 \mathrm{mg}, 0.366 \mathrm{mmol})$ in tetrahydrofuran $(10 \mathrm{~mL})$ was stirred at room temperature for 3 days. The solvent was removed in vacuo to yield the tert-butyl ether (2a) as a beige solid and used without additional purification. ${ }^{1} \mathrm{H} \mathrm{NMR}(300 \mathrm{MHz}$, $\left.\mathrm{CDCl}_{3}\right): \delta=8.2-8.0(\mathrm{~m}, 2 \mathrm{H}, \mathrm{H} 3, \mathrm{H} 4), 3.99\left(\mathrm{~s}, 3 \mathrm{H}, 6-\mathrm{CO}_{2} \mathrm{CH}_{3}\right), 3.96(\mathrm{~s}$, $\left.3 \mathrm{H}, 2-\mathrm{CO}_{2} \mathrm{CH}_{3}\right), 1.34\left(\mathrm{~s}, 9 \mathrm{H}, \mathrm{SC}\left(\mathrm{CH}_{3}\right)_{3}\right)$. Concentrated hydrochloric acid was added to the residues and heated under reflux for approximately $1 \mathrm{~h}$. A suspension formed upon subsequent cooling. The suspension was filtered to yield the titled compound as a brown solid $(12.3 \mathrm{mg}, 14 \%)$; m.p.: $188-190^{\circ} \mathrm{C}$; EI-HRMS calcd. for $\mathrm{C}_{7} \mathrm{H}_{6} \mathrm{NO}_{4} \mathrm{~S}[M+\mathrm{H}]^{+}: 200.0018$, found: $200.0019 ;{ }^{1} \mathrm{H}$ NMR $\left(800 \mathrm{MHz}, \mathrm{D}_{2} \mathrm{O}\right): \delta=8.14(\mathrm{~d}, 1 \mathrm{H}, J=8 \mathrm{~Hz}$, H5), $7.82(\mathrm{~d}, 1 \mathrm{H}, J=8 \mathrm{~Hz}, \mathrm{H} 4) ;{ }^{13} \mathrm{C}\left\{{ }^{1} \mathrm{H}\right\} \mathrm{NMR}\left(200 \mathrm{MHz}, \mathrm{D}_{2} \mathrm{O}\right): \delta=$ $171.24\left(\mathrm{C} 2-\mathrm{CO}_{2} \mathrm{H}\right), 174.22\left(\mathrm{C} 6-\mathrm{CO}_{2} \mathrm{H}\right), 152.3$ (C3), 151.9 (C6), 137.3 (C5), 136.7 (C2), 126.7 (C4)

Ligation of 3MDPA to proteins: All steps were performed at room temperature. ArgN (0.5 mL, $1 \mathrm{~mm})$ was first reduced with DTT (5 equiv) at $\mathrm{pH}$ 7.2. The solution was washed by using reaction buffer $(20 \mathrm{~mm}$ Tris$\mathrm{HCl}, \mathrm{pH}$ 7.2) and a Millipore ultrafilter with a $M_{\mathrm{W}}$ cut off of $5 \mathrm{kDa}$. A solution of DTNB (20 equiv) in reaction buffer $(5 \mathrm{~mL})$ was prepared and the protein was added drop-wise yielding a bright yellow solution. The reaction mixture was incubated at room temperature for $1 \mathrm{~h}$ and subsequently washed with reaction buffer. The solution containing the activated protein was concentrated, and a solution of 3MDPA (5 equiv) in reaction buffer $(1.5 \mathrm{~mL})$ was added to it and incubated at room temperature for $1 \mathrm{~h}$. The resulting yellow solution was concentrated and washed with additional portions of reaction buffer. The resulting ArgN-3MDPA adduct was purified by FPLC by using a MonoQ column. The same protocol was used for ligating the $\mathrm{C} 54 \mathrm{~T} / \mathrm{C} 97 \mathrm{~A} / \mathrm{Q} 69 \mathrm{C}$ triple mutant of $\mathrm{T} 4 \mathrm{ly}$ sozyme with 3MDPA and 4MMDPA. The T4 lysozyme adducts were purified by FPLC by using a MonoS column.

Protein NMR measurements: NMR measurements of $\mathrm{ArgN}$ and the C54T/C97A/Q69C triple mutant of T4 lysozyme derivatized with $3 \mathrm{MDPA}$ were performed at $25^{\circ} \mathrm{C}$ in solutions containing $2-(\mathrm{N}$-morpholino)ethanesulfonic acid buffer (MES; $20 \mathrm{~mm}$ ) at $\mathrm{pH} 6.5$ by using a Bruker $800 \mathrm{MHz}$ NMR spectrometer equipped with a cryoprobe. The PCSs were measured by measuring the cross-peak displacements in the ${ }^{1} \mathrm{H}$ dimension of ${ }^{15} \mathrm{~N}$-HSQC spectra that had been recorded in mixed solutions of paramagnetic lanthanide and diamagnetic $\mathrm{Y}^{3+}$, or in mixed solutions of $\mathrm{Co}^{2+}$ and $\mathrm{Zn}^{2+}$. PCSs were calculated as the difference of chemical shifts between the paramagnetic and diamagnetic species. The program Numbat ${ }^{[30]}$ was used to assist in the assignment of the ${ }^{15} \mathrm{~N}-\mathrm{HSQC}$ crosspeaks of the paramagnetic samples.

\section{Acknowledgements}

Financial support by the Australian Research Council is gratefully acknowledged

[1] I. Bertini, C. Luchinat, G. Parigi, Concepts Magn. Reson. 2002, 14, $259-286$.

[2] F. Rodriguez-Castañeda, P. Haberz, A. Leonov, C. Griesinger, Magn. Reson. Chem. 2006, 44, S10-S16.

[3] X. C. Su, G. Otting, J. Biomol. NMR 2010, 46, 101-112.

[4] I. Bertini, C. Luchinat, G. Parigi, Prog. Nucl. Magn. Reson. Spectrosc. 2002, 40, 249-273.

[5] M. Allegrozzi, I. Bertini, M. B. L. Janik, Y. M. Lee, G. Liu, C. Luchinat, J. Am. Chem. Soc. 2000, 122, 4154-4161.

[6] G. Pintacuda, M. John, X. C. Su, G. Otting, Acc. Chem. Res. 2007, 40, 206-212.

[7] G. Otting, J. Biomol. NMR 2008, 42, 1-9.

[8] a) C. Ma, S. J. Opella, J. Magn. Reson. 2000, 146, 381-384; b) V. Gaponenko, A. Dvoretsky, C. Walsby, B. M. Hoffman, P. R. Rosevear,
Biochemistry 2000, 39, 15217-15224; c) J. Wöhnert, K. J. Franz, M. Nitz, B. Imperiali, H. Schwalbe, J. Am. Chem. Soc. 2003, 125, 13338-13339; d) L. J. Martin, M. J. Hähnke, M. Nitz, J. Wöhnert, N. R. Silvaggi, K. N. Allen, H. Schwalbe, B. Imperiali, J. Am. Chem. Soc. 2007, 129, 7106-7113; e) T. Zhuang, H. S. Lee, B. Imperiali, J. H. Prestegard, Protein Sci. 2008, 17, 1220-1231.

[9] T. Saio, K. Ogura, M. Yokochi, Y. Kobashigawa, F. Inagaki, J. Biomol. NMR 2009, 44, 157-166.

[10] X. C. Su, B. Man, S. Beeren, H. Liang, S. Simonsen, C. Schmitz, T. Huber, B. A. Messerle, G. Otting, J. Am. Chem. Soc. 2008, 130, 10486-10487.

[11] X. C. Su, T. Huber, N. E. Dixon, G. Otting, ChemBioChem 2006, 7 , $1469-1474$

[12] P. H. Keizers, A. Saragliadis, Y. Hiruma, M. Overhand, M. Ubbink, J. Am. Chem. Soc. 2008, 130, 14802-14812.

[13] X. C. Su, K. McAndrew, T. Huber, G. Otting, J. Am. Chem. Soc. 2008, 130, 1681-1687.

[14] a) M. Prudêncio, J. Rohovec, J. A. Peters, E. Tocheva, M. J. Boulanger, M. E. P. Murphy, H. K. Hupkes, W. Kosters, A. Impagliazzo, M. Ubbink, Chem. Eur. J. 2004, 10, 3252-3260; b) M. D. Vlasie, C. Comuzzi, A. M. van den Nieuwendijk, M. Prudêncio, M. Overhand, M. Ubbink, Chem. Eur. J. 2007, 13, 1715-1723; c) P. H. Keizers, J. F. Desreux, M. Overhand, M. Ubbink, J. Am. Chem. Soc. 2007, 129, 9292-9293.

[15] a) V. Gaponenko, A. S. Altieri, J. Li, R. A. Byrd, J. Biomol. NMR 2002, 24, 143-148; b) A. Dvoretsky, V. Gaponenko, P. R. Rosevear, FEBS Lett. 2002, 528, 189-192; c) A. Leonov, B. Voigt, F. Rodriguez-Castañeda, P. Sakhaii, C. Griesinger, Chem. Eur. J. 2005, 11, 3342-3348; d) P. Haberz, F. Rodriguez-Castañeda, J. Junker, S. Becker, A. Leonov, C. Griesinger, Org. Lett. 2006, 8, 1275-1278; e) D. Häussinger, J. Huang, S. Grzesiek, J. Am. Chem. Soc. 2009, 131, 14761-14767.

[16] T. Ikegami, L. Verdier, P. Sakhaii, S. Grimme, B. Pescatore, K. Saxena, F. M. Fiebig, C. Griesinger, J. Biomol. NMR 2004, 29, 339349

[17] X. C. Su, H. Liang, K. V. Loscha, G. Otting, J. Am. Chem. Soc. 2009, 131, 10352-10353.

[18] I. Grenthe, J. Am. Chem. Soc. 1960, 82, 360-364.

[19] G. Pintacuda, A. Moshref, A. Leonchiks, A. Sharipo, G. Otting, $J$. Biomol. NMR 2004, 29, 351-361.

[20] N. Zimmermann, E. Meggers, P. G. Schultz, Bioorg. Chem. 2004, 32, $13-25$.

[21] M. John, G. Otting, ChemPhysChem 2007, 8, 2309-2313.

[22] M. John, A. Y. Park, G. Pintacuda, N. E. Dixon, G. Otting, J. Am. Chem. Soc. 2005, 127, 17190-17191.

[23] M. Sunnerhagen, M. Nilges, G. Otting, J. Carey, Nat. Struct. Biol. 1997, 4, 819-826.

[24] I. Bertini, M. B. L. Janik, Y. M. Lee, C. Luchinat, A. Rosato, J. Am. Chem. Soc. 2001, 123, 4181-4188.

[25] a) G. Pintacuda, A. Y. Park, M. A. Keniry, N. E. Dixon, G. Otting, J. Am. Chem. Soc. 2006, 128, 3696-3702; b) M. John, G. Pintacuda A. Y. Park, N. E. Dixon, G. Otting, J. Am. Chem. Soc. 2006, 128, $12910-12916$

[26] J. M. Dereppe, A. Schank, J. P. Declercq, G. Germain, M. van Meerssche, Bull. Soc. Chim. Belg. 1976, 85, 729-733.

[27] I. Bertini, C. Luchinat, G. Parigi, Solution NMR of Paramagnetic Molecules, Elsevier, Amsterdam, 2001

[28] C. Schmitz, M. John, A. Y. Park, N. E. Dixon, G. Otting, G. Pintacuda, T. Huber, J. Biomol. NMR 2006, 35, 79-87.

[29] I. Bertini, P. Kursula, C. Luchinat, G. Parigi, J. Vahokoski, M. Wilmanns, J. Yuan, J. Am. Chem. Soc. 2009, 131, 5134-5144.

[30] C. Schmitz, M. J. Stanton-Cook, X. C. Su, G. Otting, T. Huber, J. Biomol. NMR 2008, 41, 179-189.

[31] R. Koradi, M. Billeter, K. Wüthrich, J. Mol. Graphics 1996, 14, 51 55.

Received: October 21, 2009 Published online: February 16, 2010 